\title{
Peningkatan Kompetensi TIK Pendidik dalam Mengembangkan Media Pembelajaran Mobile-learning Berbasis Android Melalui Learning Cycle (3E) bagi Pendidik MAN 3 Jember
}

\author{
Arika Indah Kristiana ${ }^{1}$, Niswatul Imsiyah ${ }^{2}$, Ridho Alfarisi ${ }^{3}$, Titin Kartini ${ }^{4}$ \\ Pendidikan Matematika, FKIP Universitas Jember ${ }^{1}$ \\ Pendidikan Luar Sekolah, FKIP Universitas Jember ${ }^{2}$ \\ Pendidikan Guru Sekolah Dasar, FKIP Universitas Jember ${ }^{3}$ \\ Pendidikan Ekonomi, FKIP Universitas Jember ${ }^{4}$ \\ Kampus Tegalboto, J1. Kalimantan No.37, Krajan Timur, Sumbersari, Kec. Sumbersari, Kabupaten \\ Jember, Jawa Timur 68121 \\ Email: arika.fkip@unej.ac.id ${ }^{1}$
}

\begin{abstract}
ABSTRAK
Terdapat media digital portable yang sedang ramai digunakan di abad 21 meliputi smartphone, iphone, atau PC Tablet. Media portable memiliki kelebihan dalam penggunaan yang mudah dan harga yang terjangkau, merupakan salah satu faktor pendorong yang semakin pesatnya kesempatan penggunaan atau penerapan mobile learning sebagai alat kebiasaan baru dalam belajar, yang mendorong kebiasaan pembelajaran berbasis jarak jauh. Tujuan dari kegiatan ini untuk memberikan pendampingan dan pelatihan tentang mobile-learning berbasis android sebagai media pembelajaran kepada pendidik sekolah mitra yaitu MAN 3 Jember. Pendampingan ini dilakukan dengan memodifikasi model pembelajaran Learning Cycle (3E) yang terdiri dari 3 tahapan yaitu Exploration, Explaination dan Elaboration. Melalui kegiatan yang dilakukan pada pengabdian ini, pendidik mitra mampu untuk mengembangkan media dan memanfaatkan mobile learning sebagai media pembelajaran dalam mata pelajaran yang diampu, serta meningkatkan kompetensi TIK pendidik mitra.
\end{abstract}

Kata kunci: learning Cycle (3E), mobile-learning, kompetensi TIK

\begin{abstract}
The use of portable media such as smartphones, iPhones, PC Tablets to access online learning systems is currently in full use. The very high level of development of portable media, relatively easy use, and affordable device prices, compared to personal computers, are driving factors that are increasingly expanding the use or application of mobile learning as a new trend in learning, which forms a learning paradigm that can be done anywhere and whenever. The purpose of this activity is to provide assistance and training on Android-based mobile learning as a learning medium for partner school educators, namely MAN 3 Jember. This mentoring is done by modifying the Learning Cycle (3E) learning model which consists of 3 stages, namely Exploration, Explaination, and Elaboration. Through the activities carried out in this service, partner educators will be able to develop media and utilize mobile learning as a learning medium in the subjects they are taught, as well as improve the ICT competence of partner educators.
\end{abstract}

Keywords: learning Cycle (3E), mobile-learning, ICT competence. 


\section{PENDAHULUAN}

Pemanfaatan teknologi digital di dalam dunia pendidikan mengalami perkembangan yang sangat pesat. Dengan kecanggihan teknologi saat ini ditawarkan perubahan pembelajaran konvensional menuju pembelajaran berbasis digital. Terdapat media digital portable yang sedang ramai digunakan di abad 21 meliputi smartphone, iphone, atau PC Tablet. Media portable memiliki kelebihan dalam penggunaan yang mudah dan harga yang terjangkau, merupakan salah satu faktor pendorong yang semakin pesatnya kesempatan penggunaan atau penerapan mobile learning sebagai alat kebiasaan baru dalam belajar, yang mendorong kebiasaan pembelajarn berbasis jarak jauh (Simarmata, 2020; Pangalo, 2020). Mobile Learning adalah generasi lanjutan dari E-Learning yang menawarkan cara menarik dalam penyampaian pengetahuan, khususnya dalam proses belajar mengajar (Joshi dkk., 2015; Nuryadi, 2019).

Saat ini, perangkat mobile telah menjadi cara hidup bagi semua orang termasuk pendidik dan siswa. Komputer sudah tergantikan oleh smartphone yang dapat dapat disimpan didalam saku dan mudah dibawa kemana-mana. Penggunaan mobile-learning sebagai penunjang proses belajar mengajar ini dirasa bisa menambah fleksibilitas dalam kegiatan belajar mengajar. Mobile-learning digunakan sebagai media pelengkap pembelajaran karena memberikan kesempatan pada siswa untuk mempelajari kembali materi yang kurang dipahami dimanapun dan kapanpun, tanpa pertemuan fisik di dalam kelas antara pendidik dan siswa internet (Amirullah, 2017; Alhafidz, 2018; Rahayu, 2019).

MAN 3 Jember merupakan salah satu sekolah yang wilayahnya berada dipelosok kabupaten Jember. Lokasi MAN 3 Jember kurang lebih jaraknya $53 \mathrm{~km}$ dari kota. Meskipun jauh dari kota, namun jumlah siswa MAN 3 Jember cukup banyak. Dengan jumlah 29 kelas, 1600 siswa, dan 54 pendidik dengan dilengkapi fasilitas internet jaringan wifi. Hampir semua pendidik dan siswa di MAN 3 Jember mempunyai dan menggunakan media portable berupa smartphone berbasis android. Namun keberadaan smartphone yang mereka miliki bisa dikatakan tidak efektif dalam pemanfaatannya. Sebagaian besar siswa menggunakan smartphone untuk instagram, FB, telepon, SMS, whatsapp dan hiburan lainnya seperti musik dan permainan. Alangkah baiknya apabila smartphone yang selalu mereka bawa, bisa digunakan sebagai media mobile-learning dalam pembelajaran. Dengan media mobile learning yang memanfaatkan smartphone dapat menimbulkan antusiasme terhadap pelajaran sehingga proses pembelajaran lebih efektif dan efisien. Siswa dapat memanfaatkan smartphone yang dimiliki sebagai media sumber belajar. 
Namun, yang menjadi permasalahan di MAN 3 Jember belum ada media mobilelearning yang memanfaatkan smartphone. Salah satu faktor yang menyebabkan belum diterapkan penggunaan mobile-learning, adalah rendahnya minat pendidik dalam memanfaatkan penggunaan mobile-learning, karena penggunaan media mobile-learning tidak semata-mata mengandalkan kemampuan akademis akan tetapi juga harus didukung dengan keterampilan pendidik dalam hal penggunaan. Selain itu alasan yang lain, karena letak sekolah yang jauh dari kota sehingga menyebabkan pendidik MAN 3 Jember jarang mengikuti kegiatan workshop pemanfaatan media mobile-learning berbasis android yang diadakan oleh lembaga-lembaga pendidikan di kota Jember.

Learning cycle (3E) merupakan salah satu model pembelajaran yang tahapannya meliputi Exploration (eksplorasi), Explaination (menjelaskan) dan Elaboration (memperluas) (Rahayu, 2019; Maskur dkk, 2019; Hartini, 2020). Model pembelajaran ini dimanfaatkan sebagai tahapan dalam pengabdian dimana peserta pada model pembelajaran adalah pendidik MAN 3 Jember dan pendidik pada model pembelajaran digantikan oleh tim pengabdian. Pada tahap Exploration, pendidik diberikan kesempatan untuk mengamati perilaku siswa pada kelas masing-masing. Tahap Explaination merupakan tahap penjelasan, yaitu tahap yang diharapkan terjadinya proses pemahaman konsep-konsep baru dengan konsep yang telah dimiliki pendidik. Pendidik mendapatkan penjelasan dari tim pengabdian. Tahap Elaboration merupakan tahap penerapan konsep baru yang telah diperoleh pada tahap sebelumnya. Dari tiga tahapan pada learning cycle (3E) tersebut, diharapkan pendidik mitra MAN 3 Jember dapat mengembangkan sendiri media pembelajaran mobile-learning berbasis android.

Pengabdian ini bertujuan agar pendidik di MAN 3 Jember dapat memanfaatkan mobile-learning berbasis android sebagai media pembelajaran sehingga pendidik mitra memahami dan mengembangkan media pembelajaran mobile-learning berbasis android dan pendidik mitra memahami cara memanfaatkan mobile-learning sebagai media pembelajaran dalam upaya meningkatkan kompetensi TIK.

\section{METODE}

Metode pelaksanaan kegiatan yang digunakan dalam kegiatan pengabdian adalah model Learning Cycle (3E) yang terdiri dari Exploration, Explaination dan Elaboration. Adapun tahapan pelaksanaan pengabdian yang dilakukan kepada mitra adalah sebagai berikut.

1. Tahap Exploration 
Pada tahap ini dilakukan kepada semua pendidik di sekolah mitra (i) Menjelaskan tujuan umum dari pengabdian yang diberikan (ii) Meminta pendidik untuk mengamati situasi dan kebiasaan dari peserta didik pada kelas masing-masing (iii) Memberikan kesempatan kepada pendidik untuk memilih tema atau materi yang dapat diterapkan dalam penggunaan media pembelajaran mobile-learning berbasis android. (iv) Meminta pendidik mendeskripsikan topik pembelajaran yang dipilih (v) Memberikan kesempatan kepada pendidik untuk menggali situasi pembelajaran yang terjadi dalam kelasnya. (vi) Membagi pendidik menjadi beberapa kelompok sesuai dengan kelas .

\section{Tahap Explaination}

Pada tahap ini dilakukan pemberian materi kepada pendidik mitra: (i) Memberikan contoh-contoh media pembelajaran yang dibuat menggunakan mobile-learning berbasis android sehingga pendidik merasa tertarik dan termotivasi untuk belajar mengembangkan sendiri media pembelajaran. (ii) Memberikan materi tentang media pembelajaran mobile-learning berbasis android dan pemanfaatannya dalam pembuatan media pembelajaran. (iii) Memberikan contoh media pembelajaran mobile-learning berbasis android.

\section{Tahap Elaboration}

Pada tahap ini, dilakukan pembimbingan pembuatan media pembelajaran mobilelearning berbasis android (i) Meminta pendidik mitra untuk menyiapkan materi yang telah dipilih pada tahap sebelumnya; (ii) Meminta pendidik mitra untuk membentuk kelompok sesuai kelas yang diajar, setiap kelompok didampingi oleh satu orang dari tim pengabdian. (iii) Meminta pendidik mitra untuk bergabung dengan kelompoknya dan bekerja sama dalam pembuatan media pembelajaran dengan bimbingan dari tim pengabdian.

\section{HASIL, PEMBAHASAN, DAN DAMPAK}

Sesuai dengan tahapan dalam Learning Cyle (3E) yang terdiri dari (1) tahap Exploration, (2) tahap Explaination, dan (3) tahap Elaboration. Pelaksanaan pengabdian yang dilakukan dengan memanfaatkan tahapan dalam Learning Cycle (3E) dijelaskan sebagai berikut.

1. Persiapan pelaksanaan pengabdian

Kegiatan ini dilakukan koordinasi tim pengabdian yang terdiri dari tim pengusul dan dibantu dengan 4 mahasiswa. Koordinasi yang dilakukan adalah survey lokasi 
pengabdian, penyusunan modul pelatihan sesuai tahapan learning cycle (3E) yaitu tahap Explaination. Koordinasi awal dengan mitra adalah koordinasi waktu pelaksanaan pelatihan dan pendampingan pada pendidik sekolah mitra.

Persiapan kedua adalah penyusunan modul pelatihan. Modul pelatihan yang dipersiapkan oleh tim pengabdian adalah (1) modul pembuatan video pembelajaran berbantuan Bandicam, (2) modul google classroom, (3) modul cloud classroom dan (4) modul pembuatan evaluasi pembelajaran berbantuan quizzi.

\section{Tahap Exploration}

Pada tahap ini dilakukan kepada semua pendidik di sekolah mitra: (i) Menjelaskan tujuan umum dari pengabdian yang diberikan Dalam kondisi masa pandemi covid-19 ini, kegiatan pengabdian tetap dilaksanakan dengan menerapkan protokol kesehatan sesuai dengan anjuran pemerintah. Tujuan secara umum dari pengabdian ini adalah memberikan pelatihan dan pendampingan pada pendidik MAN 3 Jember sebagai mitra untuk meningkatkan pengembangan media pembelajaran mobile-learning berbasis android yang sangat bermanfaat dalam pembelajaran daring. Koordinasi awal dengan mitra adalah koordinasi waktu pelaksanaan pelatihan dan pendampingan pada guruguru mitra.
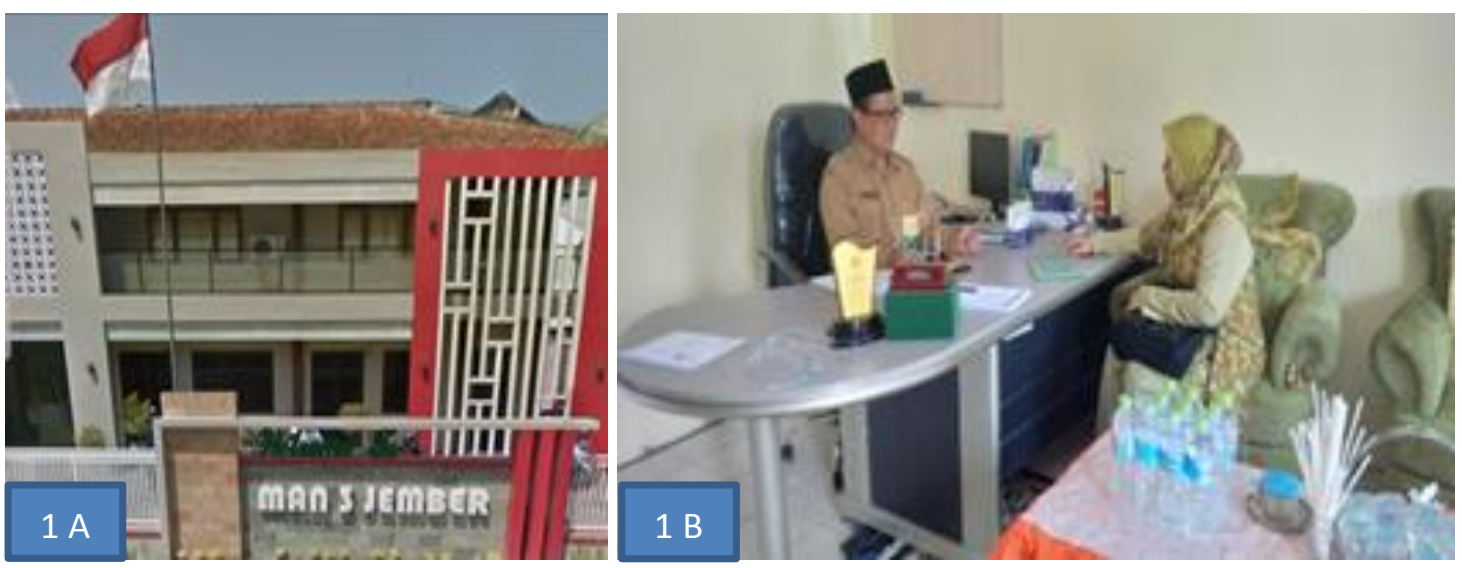

Gambar 1 A Photo MAN 3 Jember dari depan dan Gambar 1 B Koordinasi Tim

Pengabdi dengan Kepala Sekolah MAN 3 Jember

(ii) Meminta pendidik untuk mengamati situasi dan kebiasaan dari peserta didik pada kelas masing-masing. MAN 3 Jember memiliki website tentang e-learning, tetapi terkadang sering bermasalah di saat tertentu sehingga dikenalkan juga tentang pembuatan kelas menggunakan google classroom dan cloud classroom. Semakin banyak pilihan, pendidik sekolah mitra dapat memilih mana yang tidak memberatkan paketan data siswa dan memudahkan akses bagi siswa. (iii) Memberikan kesempatan kepada pendidik untuk memilih tema atau materi yang dapat diterapkan dalam 
penggunaan media pembelajaran mobile-learning berbasis android. Pendidik di sekolah mitra diminta untuk menyiapkan materi sebagai bahan pengembangan media pembelajaran berupa video pembelajaran. (iv) Meminta pendidik mendeskripsikan topik pembelajaran yang dipilih dan menyiapkan slide presentasi sebagai penunjang pembuatan video pembelajaran. (v) Memberikan kesempatan kepada pendidik untuk menggali situasi pembelajaran yang terjadi dalam kelasnya. Kegiatan ini bertujuan pendidik dapat memilih media pembelajaran yang akan dikembangkan dan pemanfaatan kelas yang dipilih. (vi) Membagi pendidik menjadi beberapa kelompok sesuai dengan kelas Karena jumlah pendidik di sekolah mitra pada MAN 3 Jember ada 54 orang, akhirnya dibagi menjadi 6 kelompok untuk memudahkan dalam proses pendampingan pembuatan media dan kelas online. Masing-masing kelompok terdiri dari 8 - 9 pendidik mitra, yang nantinya didampingi oleh satu orang dari Tim pengabdian.

\section{Tahap Explaination}

Pada tahap ini, terdapat beberapa yang dilakukan, yaitu (i) Memberikan contoh media pembelajaran yang dibuat menggunakan mobile-learning berbasis android sehingga pendidik merasa tertarik dan termotivasi untuk belajar mengembangkan sendiri media pembelajaran. Media pembelajaran mobile-learning berbasis android mempunyai makna media pembelajaran yang dapat didownload dan dapat diaplikasikan di HP android. Dengan kondisi masa pandemi saat ini dimana pemerintah menganjurkan pelaksanaan pembelajaran daring, pendidik mitra juga diminta untuk memanfaatkan android dalam pembelajaran. Adapun media pembelajaran yang dapat digunakan adalah video pembelajaran, pembuatan kelas atau evaluasi pembelajaran dengan aplikasi quizizz. Berdasarkan pengalaman semester sebelumnya, pendidik mitra lebih tertarik dalam pembuatan video pembelajaran. Sehingga Tim pengabdian lebih fokus pada pendampingan pembuatan video pembelajaran. (ii) Memberikan materi tentang media pembelajaran mobile-learning berbasis android dan pemanfaatannya dalam pembuatan media pembelajaran. Pemberian materi dilakukan dalam bentuk pelatihan. Materi pelatihan dapat dilihat pada tabel 1 . 
Tabel 1.Tim Pengabdian dan Materi Pelatihan

\begin{tabular}{cll}
\hline No & \multicolumn{1}{c}{ Materi pelatihan } & \multicolumn{1}{c}{$\begin{array}{c}\text { Tim pengabdian yang } \\
\text { bertanggung jawab }\end{array}$} \\
\hline 1 & Pembuatan kelas dengan Google Classroom & Niswatul Imsiyah, S.Pd., M.Pd \\
2 & Pembuatan kelas dengan Cloud Classroom & Niswatul Imsiyah, S.Pd., M.Pd \\
3 & $\begin{array}{l}\text { Pembuatan Video Pembelajaran dengan } \\
\text { Bandicam }\end{array}$ & $\begin{array}{l}\text { Dr. Arika Indah Kristiana, S.Si., } \\
\text { M.Pd }\end{array}$ \\
4 & $\begin{array}{l}\text { Pembuatan evaluasi pembelajaran dengan } \\
\text { Quiz }\end{array}$ & \begin{tabular}{l} 
Dr.Pd Arika Indah Kristiana, S.Si., \\
\hline
\end{tabular}
\end{tabular}

Pada tabel 1 terlihat pembagian penanggung jawab materi untuk masing-masing sesi pelatihan, pelatihan meliputi Pembuatan kelas dengan Google Classroom, Pembuatan kelas dengan Cloud Classroom, Pembuatan Video Pembelajaran dengan Bandicam, Pembuatan evaluasi pembelajaran dengan Quiz.
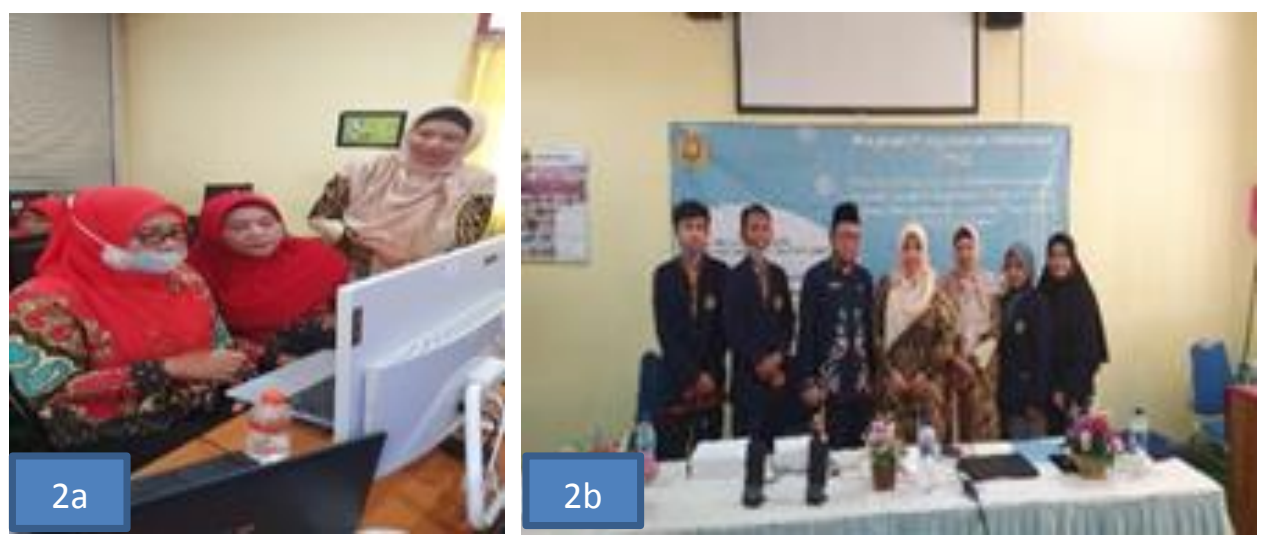

Gambar 2a. Dokumentasi Kegiatan Pelatihan terlihat interaksi antara tim pengabdi dengan pendidik di MAN 3 Jember dan Gambar 2b. Sesi photo pada bagian akhir Kegiatan Pelatihan

(iii) Memberikan contoh-contoh media pembelajaran mobile-learning berbasis android. Karena MAN 3 Jember telah memiliki e-learning, sehingga pendidik mitra lebih berminat pada pembuatan video pembelajaran. Contoh video pembelajaran adalah produk dari Tim pengabdian.

\section{Tahap Elaboration}

Pada tahap ini, dilakukan pendampingan pembuatan media pembelajaran mobilelearning berbasis android fokus pada pembuatan video pembelajaran. (i) Meminta pendidik mitra untuk menyiapkan materi yang telah dipilih pada tahap sebelumnya. Pada tahap Exploration, pendidik diminta untuk memilih topik/materi dan menyiapkan slide presentasi. Sehingga pada tahapan ini, pendidik mitra harus sudah mempunyai slide presentasi yang dijadikan video pembelajaran. Hampir seluruh 
pendidik mitra sudah menyiapkan slide presentasi. (ii) Meminta pendidik mitra untuk membentuk kelompok sesuai kelas yang diajar, setiap kelompok didampingi oleh satu orang dari tim pengabdian. Berdasarkan kelompok yang telah dibentuk pada tahap Exploration, didampingi oleh satu orang Tim pengabdian. Meminta pendidik mitra untuk bergabung dengan kelompoknya dan bekerja sama dalam pembuatan media pembelajaran dengan bimbingan dari tim pengabdian. Pendampingan dilakukan per kelompok. (iii) Meminta pendidik mitra untuk bergabung dengan kelompoknya dan bekerja sama dalam pembuatan media pembelajaran dengan bimbingan dari tim pengabdian.

\section{KESIMPULAN}

Berdasarkan beberapa kegiatan yang dilakukan dapat disimpulkan bahwa Pendidik mitra telah memahami dan mengembangkan media pembelajaran mobile-learning berbasis android berupa video pembelajaran selama mengikuti kegiatan pengabdian ini. Pada tahap Elaboration, pendidik mitra termotivasi untuk membuat media pembelajaran video pembelajaran menggunakan bandicam karena aplikasi ini ukurannya kecil sehingga ringan di laptop. Pada tahap Explaination untuk materi pembuatan kelas tidak tertarik untuk dilakukan karena merasa pihak sekolah sudah menyediakan e-learning. Pendidik mitra telah memanfaatkan mobile-learning sebagai media pembelajaran daring saat ini dalam upaya meningkatkan kompentensi TIK melalui video pembelajaran.

\section{UCAPAN TERIMAKASIH}

Kami ucapkan terima kasih kepada LP2M Universitas Jember telah yang telah memberikan dukungan dana dalam pelaksanaan pengabdian masyarakat melalui Hibah Program Pengabdian Kemitraan (PKM) 2020.

\section{DAFTAR PUSTAKA}

Alhafidz, M. R. L., \& Haryono, A. 2018. Pengembangan mobile learning berbasis android sebagai media pembelajaran ekonomi. Jurnal Pendidikan Ekonomi, 11(2), 118-124.

Amirullah, G., \& Hardinata, R. 2017. Pengembangan mobile learning bagi pembelajaran. Jurnal Kesejahteraan Keluarga dan Pendidikan, 4(02), 97-101.

Hartini S, Abyati D S, and Abdul S M, (2020). Developing high school physics teaching materials through 7E learning cycle model. Journal of Physics: Conference Series. 
Journal of Physics: Conference Series $1422 \quad(2020) 012032$. https://doi.org/10.1088/1742-6596/1422/1/012032

Joshi, R., Shete, V. V., \& Somani, S. B. (2015). Android based smart learning and attendance management system. International Journal of Advanced Research in Computer and Communication Engineering, 4(6), 256-260.

Maskur, R., Latifah, S., Pricilia, A., Walid, A., \& Ravanis, K. (2019). The 7E Learning Cycle Approach to Understand Thermal Phenomena. Jurnal Pendidikan IPA Indonesia, 8(4), 464-474.

Nuryadi, N. 2019. Pengembangan Media Matematika Mobile Learning Berbasis Android ditinjau dari Kemampuan Pemecahan Masalah. Jurnal pendidikan surya edukasi (JPSE), 5(1), 1-13.

Pangalo, E. (2020). PEMBELAJARAN MOBILE LEARNING UNTUK SISWA SMA. Jurnal Teknologi Pendidikan, 5(1), 38-56. Retrieved from http://139.59.120.216/index.php/jtp/article/view/2851

Rahayu, S. 2019. Penerapan Model Pembelajaran Learning Cycle-5E dalam Pembelajaran IPA. CV Beta Aksara.

Simarmata, J. et al. (2020). Teknologi Informasi: Aplikasi dan Penerapannya. Medan: Yayasan Kita Menulis. 